Fecha de recepción: marzo 2021 Fecha de aceptación: abril 2021 Versión final: mayo 2021

\section{Epistemología del diseño y ficción fantástica desde el sur: As boas maneiras (Los buenos modales) ${ }^{1}$}

Eduardo A. Russo ${ }^{(1)}$

\begin{abstract}
Resumen: El artículo examina el caso del largometraje brasileño As boas maneiras (los buenos modales), de Juliana Rojas y Marco Dutra, como una experiencia de diseño audiovisual enmarcada en una epistemología del sur. A partir del cuestionamiento de las líneas abismales trazadas en su diégesis, el film apunta a un horizonte posabismal en el campo del cine fantástico realizado en nuestro continente. Por otra parte, las interrelaciones entre tecnología, arte y diseño audiovisual ofrecidas por el film desafían las soluciones estándar del cine predominante y abren una activa zona de experimentación en las relaciones entre diseño y ficción en el cine latinoamericano.
\end{abstract}

Palabras clave: Cine - Diseño - Ficción - Epistemología - Arte.

[Resúmenes en inglés y portugués en las páginas 98-99]

${ }^{(1)}$ Eduardo A. Russo. Doctor en Psicología Social. Crítico, docente e investigador de cine y artes audiovisuales Universidad Nacional de La Plata (Argentina). Dirige el Doctorado en Artes de la Facultad de Bellas Artes (UNLP). Profesor de la Universidad de Palermo en el Área Audiovisual. Jurado de Festivales y curador de muestras internacionales sobre cine, artes audiovisuales y electrónicas en el campo latinoamericano. Investigador y Evaluador Programa de Incentivos CyT. Evaluador de contenidos de ciclos documentales del sistema de Televisión Digital Argentina. Dirige la publicación Arkadin -Estudios sobre cine y artes audiovisuales- de la FBA-UNLP. 


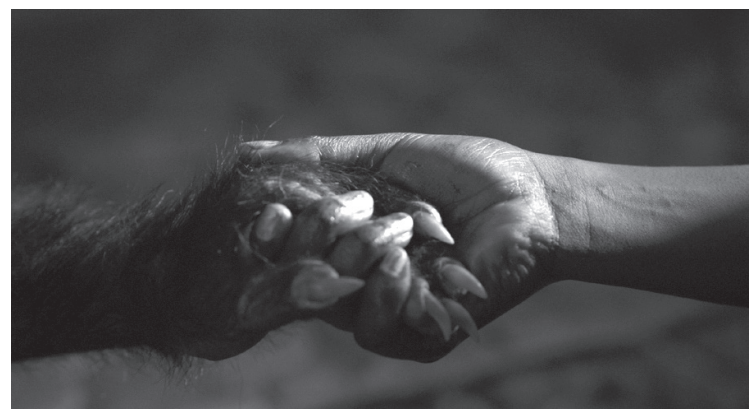

Figura 1.

As boas maneras"

No es sencillo incorporar el largometraje brasileño As boas maneiras (Los buenos modales) (Rojas \& Dutra, 2017) en un marco identificable. Su pertenencia transgenérica lo hace transitar el melodrama familar, la película de terror y el cuento de hadas para adultos. Por otra parte, en tanto relato no oculta una dimensión de conciencia y crítica social, comportando además una historia de deseo y amor que contiene un decisivo ángulo queer. Abundan ángulos para referenciarla, pero ninguno de ellos agota una propuesta que, por otra parte, dedica un aspecto decisivo al diseño audiovisual en su realización. $\mathrm{Al}$ crear un mundo ficcional alternativo, no regulado por las políticas propias de alguno de los realismos cinematográficos largamente activos en el cine latinoamericano, Rojas y Dutra se han propuesto elaborar una fábula donde la mirada y la escucha del espectador se ofrecen a la suspensión de la incredulidad ante un mundo imaginado y hecho concreto mediante operaciones que, como ocurre con los marcos genéricos citados, también desafían códigos usuales para narrar lo que, en términos un tanto simplificadores, podría denominarse como una historia de licantropía propia del relato fantástico.

Es posible apreciar las distintas operaciones del diseño audiovisual en el interior de As boas maneiras en el marco de lo que se ha designado como epistemologías del sur (De Sousa Santos y Meneses, 2014; Meneses y Vidaseca, 2018). Epistemologías que hacen a órdenes cognitivos y modos de organización sociopolítico, con implicancias simbólicas e imaginarias, e inciden de modo creciente en distintos campos del diseño, entre los cuales se ubican los aquí examinados, que hacen a la creación de mundos y relatos ficcionales en pantalla. Si el film parte de situaciones dramáticas reconocibles, como aquellas propias del melodrama familiar, y particularmente activas en la telenovela, en un escenario doméstico atravesado por conflictos sentimentales y de clase, lo hace para posteriormente enrarecerlas y orientarlas hacia rumbos difícilmente previsibles. Al comienzo de As boas maneiras, una joven embarazada, Ana, busca una niñera para su hijo aún no nacido. Clara llega a su casa y es la elegida. El caso es que Ana es blanca y rica, Clara es negra y pobre. Lo común en ambas es que están solas. Nace así una relación que desde el cuidado inicial pasa a la ternura, luego a la pasión amorosa mezclada con un vínculo más oscuro, 
que incluye la criatura que se está gestando en vientre de Ana y que provocará un giro trágico, que abrirá una nueva historia. A partir de allí, la historia de As boas maneiras es la de Clara y el pequeño Joel, un niño nacido como lobisomem, el hombre lobo de la tradición luso-brasileña, quienes viven buscando el mantenimiento de una humanidad trabajosamente adquirida y en riesgo de ceder ante la licantropía que acecha. No es necesario proseguir aquí la descripción narrativa. Sólo apuntaremos que la construcción del film convierte no sólo en protagónica a la seducción de su relato, sino a las formas por las cuales éste se hace plasma en la puesta en escena de un universo fantástico cuyos elementos perceptibles imponen su convicción al espectador mediante diversos procesos de diseño. Sus propuestas remiten a tradiciones consolidadas de lo fantástico en el cine, pero a la vez las cuestionan y hasta subvierten, desde una epistemología que desafía el dictado del canon y configura sus imágenes.

\section{Espacios oníricos y líneas abismales}

El punto de partida de As boas maneiras fue el sueño de uno de sus directores, Marco Rojas. En aquel sueño dos mujeres, viviendo en un lugar aislado, cuidaban a un niño monstruo (Legrand, 2017) El film que comenzó a tomar forma a partir de ese sueño debió convertir a ese "lugar aislado" en un espacio a habitar, tanto por parte de sus personajes como de sus espectadores, hasta que culminó siendo la gran ciudad innominada que se aprecia en la película, que remite de modo inequívoco a São Paulo, aunque traduciéndola bajo coordenadas propias de la fábula. La ciudad imaginada en el film está estructurada como un espacio activo, un diseño urbano que alegoriza esos trazados divisorios que en las epistemologías del sur se designan como líneas abismales.

Para Boaventura de Sousa Santos, las líneas abismales consisten en un régimen de delimitaciones de la experiencia humana que demuestra especial eficacia en la partición y segregación de sectores sociales. Las fronteras así delineadas no solamente demarcan divisiones entre partes de lo visible, sino también, ejerciendo un poder de exclusión decisivo y radical, determinan zonas de visibilidad y y de invisibilidad:

Éste consiste en un sistema de distinciones visibles e invisibles, las invisibles constituyen el fundamento de las visibles. Las distinciones invisibles son establecidas a través de líneas radicales que dividen la realidad social en dos universos, el universo de "este lado de la línea" y el universo del "otro lado de la línea". La división es tal que "el otro lado de la línea" desaparece como realidad, se convierte en no existente, y de hecho es producido como no-existente (De Sousa Santos, 2010, 11-12)

Aunque en su estructura fundamental las líneas abismales operan de modo subterráneo, ajenas a la percepción (lo que hace más insidiosa su eficacia), esta arquitectura no perceptible suele determinar construcciones que sí pertenecen al terreno de lo palpable, particularmente en términos de disposición espacial. En su andamiaje invisible, las líneas 
abismales no solamente determinan las zonas en las cuales se dispondrá lo aceptable y lo no aceptable, lo digno de ser incluído y lo pasible de ser expulsado, sino que, en su eficacia última, son capaces no solamente de desplazar aquello que debe ser excluído hacia un rango de invisibilidad, sino que también dicha demarcación se borra a sí misma, como si pudiera contener en sí el conjunto de lo existente. Lo que queda por fuera será, en todo caso, algo condenado a no existir. En su imaginaria geografía urbana, As boas maneiras integra un diseño de interiores, una arquitectura y un urbanismo que es estructurado a partir de un basamento de líneas abismales, cuya operación queda verificada en diversas superficies perceptibles en pantalla. La primera mitad de la película transcurre en una São Paulo cuasi onírica, apta para posible reconocimiento del espectador, pero de modo traspuesto, acompañado por un efecto de desfamiliarización que rehúye cualquier apelación al color local, o a la iconografía realista de la gran metrópoli moderna. El espacio propio de la gran urbe, con sus zonas residenciales de altos edificios con sistemas propios de vigilancia privada, sus parques y paseos peatonales, contrasta con las barriadas pobres donde se apiñan las casas o cuartos familiares donde moran aquellos que trabajan en los barrios acaudalados. Un puente permite atravesar el río que tanto física como simbólicamente divide una y otra área de la gran ciudad. Pero el espacio realista de la ciudad donde transitan decenas de millones de vidas humanas se ve traspuesto en un territorio interconectado por pasajes inciertos. En la segunda mitad del film, tras una elipsis durante la cual al espectador se le revela de inmediato que han pasado varios años, la acción se desplaza al espacio de un barrio popular cuya atmósfera es más bien diurna y laboriosa. Allí se trabaja, se va a la escuela y se ejerce una socialidad horizontal, que en los pocos momentos de ocio o esparcimiento apuntan a un distante centro comercial, el Shopping Bosque Cristal, donde es posible acceder a la posibilidad de un paseo y que será escenario de una culminación sangrienta. Todas expansiones a partir de un sueño inicial, que no abandonan su carácter dependiente de lo onírico.

Los realizadores de As boas maneiras han destacado que un referente crucial, dentro de lo cinematográfico, de As boas maneiras, ha sido otro film inclasificable: The Night of the Hunter (Laughton, 1955). De allí proviene la presencia y el punto de vista de los niños, el legado del expresionismo cinematográfico y sus espacios casi alucinatorios, la mixtura entre el relato de terror y el cuento de hadas, que no desestima un activo fondo social del relato. Es revelador cómo los procesos creativos de aquel film clásico anticipan una concepción de diseño que atraviesa la dirección, la fotografía, el arte y los efectos visuales, así como la interrelación entre imágenes y sonido (Turner, 2017). Pero si su referente ya era una rara avis en el cine fantástico, las torsiones que desde el sur elaboran Rojas y Dutra hacen del film presente un caso doblemente innovador.

El trazado de líneas abismales elabora, desde el mismo inicio de As boas maneiras, una cartografía del poder y sus relaciones, más allá de los cánones propios del discurso realista y, detalle nada menor tratándose de una fábula como ésta, también apartándose de las coordenadas de un posible realismo mágico. En lugar de ello, dicha cartografía convoca el poder de lo fantástico, con su llamado a lo siniestro y la acechanza que lo sobrenatural extiende sobre lo natural y cotidiano. Los espacios interiores del departamento de Clara, la futura madre del niño-lobo, integran en su diseño los atributos modernistas de un amplio apartamento paulista y los elementos iconográficos de una hacienda de Cerrado 
brasileño, con sus trofeos y sus reminiscencias coloniales. En cuanto a los exteriores, las imponentes torres residenciales se erigen en un paisaje urbano que inclina a una apreciación de orden pictórico en la pantalla, a lo que contribuyen el experto uso del matte painting, esa técnica que permite combinar en pantalla zonas tomadas en espacios reales con otras que muestran elementos pintados en superficies transparentes, creado por el artista brasileño Eduardo Schaal. Los exteriores son así compuestos no solamente como una suerte de set cinematográfico, sino que en algunos pasajes convocan a una mirada gráfica o pictórica. En cuanto a los efectos visuales, obtenidos por procedimientos mixtos, entre lo analógico y la composición digital, las imágenes de As boas maneiras diseñan un entorno de carácter onírico y predominantemente nocturno. La virtuosa fotografía de Rui Poças se complementa y fusiona con los detallados efectos visuales generados por CGI (Computer Graphics Imagery), en construcciones hiperrealistas en su cuidado del detalle, aunque no obsesionadas por el realismo fotográfico. En ese sentido, las lineas abismales de As boas maneiras dependen del diseño como parte constitutiva del poder de la ficción. En las últimas décadas, el concepto de design fiction, traducible como diseñoficción (en consonancia con el conocido campo de la ciencia ficción) ha sido profusamente desarrollado justamente en íntima relación con el citado género. Pero es admisible considerar su presencia en propuestas ficcionales que construyan mundos posibles que opten por su condición alternativa, que requieran de la invención de espacios, de objetos o criaturas que se integren en una consistencia imaginaria, por fuera de la usual ciencia ficción (Franke, 2010; Dunne \& Raby, 2013). Este es precisamente es el caso de As boas maneiras, con su ciudad, sus locaciones ficcionales, sus personajes y muy particularmente su pequeño lobisomem, que configuran un mundo alternativo de rotunda consistencia imaginaria. La forma en se conjugan los recursos de la cinematografía, la dirección de arte, los efectos visuales (integrando técnicas tradicionales de los llamados "efectos prácticos", obtenidos mediante elementos físicos dispuestos a ser capturados por la cámara y gráficos digitales) y el diseño sonoro en el film conforman un mundo diegético compacto, en el que As boas maneiras sumerge a su espectador y lo dispone a ser afectado por las peripecias de sus criaturas.

\section{Cómo diseñar un lobisomem}

Un núcleo privilegiado del diseño ficción en el cine radica en la creación de criaturas imaginarias. En este caso, se trata de ese ser sobrenatural de larga trayectoria en la cultura popular como lo es el hombre lobo, el lobisomem de la tradición portuguesa y brasileña (término del cual deriva la versión en español del lobisón, o lobizón, para designar al licántropo). Los realizadores del film han resaltado la gran popularidad de la figura del lobisomem como monstruo legendario en el sur brasileño (Legrand, 2017). Las referencias con las que se otorga presencia en pantalla al niño-lobo del film pertenecen tanto al largo linaje de los hombres lobo cinematográficos y, por otra parte, remite a los contornos propios de la tradición popular brasileña. Pero en las operaciones planteadas por los realizadores, en su exploración de las líneas abismales y su posible traspaso hacia posibi- 
lidades post abismales, plasmar esta criatura particular comporta algunos giros cruciales. En As boas maneiras, el niño-lobo lo es por linaje, ajeno al carácter de maldición que asume la licantropía en la tradición europea. Simplemente es el hijo de un licántropo que tuvo una fugaz relación con su madre, a quien la licantropía le arriba no por una mordedura de hombre-lobo sino por engendrar un hijo con esa condición aún antes de nacer. El niño lobo es ajeno también a su inscripción en los órdenes propios del cristianismo. Aquí no hay bala de plata ni posibilidad de defenderse del ataque del lobizón. Tampoco se puede anular la condición licántropa por medio de la intervención divina. Solo está el llamado de una naturaleza oscura, como la que lo lleva a desgarrar mortalmente el útero de su madre en el momento del parto, al nacer como monstruo y no como humano. Por otra parte, el linaje patriarcal que se evidencia en numerosas versiones de las historias de licantropía, donde el padre debe terminar con la existencia de su propio hijo licántropo, aquí se ve reemplazado por los lazos no de una, sino de una doble maternidad. Todo ese entramado se condensa en la figura del niño-lobo. En el momento culminante que marca un giro radical a mitad del film, el del nacimiento sangriento, el desafío que asumieron los creadores del film fue crucial, al proponerse mostrar la criatura recién nacida: ¿Cómo diseñar un niño-lobo que es, más bien un lobo-niño? ¿Cómo componer un ser que aúna por partes iguales agresividad y desvalimiento, monstruosidad y una apelación a la ternura que llevará a Ana a proponerse como su madre para todo el resto de su vida, y por cierto de la película?

El tránsito de la metamorfosis, en la tradición de los films de hombres-lobo, conduce del estado humano a la conversión en animal monstruoso. Resulta casi ritual ese instante inmediatamente posterior a la aniquilación del monstruo, en que una breve metamorfosis revela la devolución de una humanidad póstuma. En la recuperación de la forma humana queda plasmada la obtención de la paz eterna y hasta la instalación de cierto estado de inocencia. En la resolucion canónica, el humano no es el culpable, sino el monstruo que alojaba en su interior y volvía durante cada luna llena. En As boas maneiras, un sistema de inversiones determina la condición y las peripecias del lobo-niño: nace lobizón y mata a su madre en un parto sangriento. Conquista trabajosamente el estado de humano a condición de controlar su instinto o contenerlo mediante el encierro en cada ciclo de luna llena. El trance de la metamorfosis, minuciosamente expuesto a lo largo del horror film en el cine contemporáneo gracias a las innovaciones en efectos especiales, en esta película es llamativamente escamoteado. Acaso porque la forma humana de la pequeña criatura es lo inestable, lo que no termina de afirmarse y está permanementemente en riesgo desde el momento en que su verdadera naturaleza será reclamada por la luna llena. Cada retorno al estado humano, más bien, es evidenciado con más detale que el afloramiento del lobo oculto.

\section{Un entrelazamiento post abismal}

De todas maneras, gracias a la deriva fatalista propia del relato de licántropos, todo se sale de cauce, conduciendo al conflicto final. No hay en el film ningún efecto de cierre, 
ningún triunfo póstumo de una humanidad impoluta revelada ante el cadáver del monstruo. En lugar de ello, el desenlace de As boas maneiras elige, al mostrar cómo se levanta en sus patas traseras el pequeño lobisomem para asumir, de la mano con su madre, su condición humana ante el combate final, mostrar un modo de resistencia, en la cual lo humano y lo animal se vinculan y lo monstruoso queda traspasado. Así lo condensan esas manos estrechadas que presenta la imagen expuesta al comienzo de este artículo, la de Joel, entre lobo y niño, unida a la de Clara. Manos que se han convertido en algo así como el emblema o leit motif de la difusión promocional del film a escala internacional. La búsqueda de As boas maneiras no se dirige linealmente a la denuncia social, sino a la interrogación sobre las categorías usuales de localización y jerarquización demarcadas por líneas abismales en términos de clase, de raza, de género y de especie, a través de la hibridación propiciada por lo monstruoso como agente cuestionador, y lo hace mediante el diseño de su mundo imaginario. Si en su primera mitad los recursos de diseño audiovisual se orientan a trazar dicho conflicto a través de la creación de espacios interiores y exteriores que se organizan según un sistema de líneas abismales que regulan su arquitectura y urbanismo imaginarios, en la segunda parte el diseño se condensa en el protagonismo de su personaje central, el niño-lobo cuya aparición genera los momentos culminantes de su historia. Al concentrar el diseño en la creación de una criatura ficcional que condensa tanto la operación de ese trazado abismal, como la posibilidad, en una utopía cruenta pero fiel a sus premisas, de un lazo post abismal entre sus criaturas ficcionales, As boas maneiras se convierte en un relevante aporte que, desde el sur, revitaliza el campo de lo fantástico en el cine contemporáneo.

\section{Notas}

1. Este artículo retoma y amplía los desarrollos expuestos en una publicación anterior del autor, "Líneas abismales y estéticas fronterizas", publicados en la revista Arte e Investigación, de la Facultad de Artes de la Universidad Nacional de La Plata, Argentina. Esta publicación, como la anterior, se enmarcan en el proyecto de investigación Transiciones $y$ tránsitos en el cine contemporáneo. Relocalizaciones, apropiaciones y continuidades de una experiencia en expansión, entre el cine y los nuevos medios, radicado en el IPEAL (Instituto para la Enseñanza del Arte en América Latina), FdA-UNLP (proyecto SECyT B353).

\section{Referencias}

De Sousa Santos, B. (2010). Para descolonizar Occidente. Más allá del pensamiento abismal. Ciudad Autónoma de Buenos Aires, Argentina: Prometeo, CLACSO.

De Sousa Santos, B. y Meneses, M. P. (eds.) (2014) Epistemologías del sur (Perspectivas). Madrid, España: Akal 
Dunne, A. \& Raby, F. (2013) Speculative Everything. Design, Fiction and Social Dreaming. Cambridge, Massachussetts, Estados Unidos. MIT Press.

Franke, Björn (2010) Design Fiction is Not Necessarily about the Future. Bjornfranke. com. Recuperado de: http://www.bjornfranke.com/_texts/franke_2010_design_fiction_is_not_necessarily_about_the_future.pdf

Laughton, C. (Director). (1955). The Night of the Hunter [La noche del cazador] [Película]. Estados Unidos: United Artists.

Legrand, X. (2017). Interview with Juliana Rojas and Marco Dutra (Good Manners) [Entrevista con Juliana Rojas y Marco Dutra] Rober Awards. LIFF2017. Recuperado de https://roberawards.com/film/lff2017-interview-with-juliana-rojas-and-marco-dutragood-manners/

Meneses, M. P. y Vidaseca, K (coord.) (2018) Epistemologías del sur/Epistemologías do Sul. Ciudad Autónoma de Buenos Aires, Argentina, CLACSO.

Rojas, J. y Dutra, M. (Directores.). (2017). As boas maneiras [Los buenos modales] [Película]. Brasil: Dezenove Som e Imagem, Good Fortune Films, Urban Factory.

Russo, E. A. (2021) Líneas abismales y estéticas fronterizas. As boas maneiras y Bacurau. En revista Arte e Investigación, Número especial: Arte, Tecnología y Colonialidad. Papel Cosido, Facultad de Artes, Universidad Nacional de La Plata.

Turner, G (2017) Creating The Night of the Hunter. American Cinematographer, American Society of Cinematographers, August 2. Recuperado de:

https://ascmag.com/articles/flashback-the-night-of-the-hunter

Abstract: The article examines the case of the Brazilian feature film As boas maneiras (The Good Manners), by Juliana Rojas and Marco Dutra, as an audiovisual design experience framed in a Episthemology of the South. Starting from the questioning of the abyssal lines drawn in its diegesis, the film points to a post-abyssal horizon in the field of fantastic cinema made in Latin America. On the other hand, the interrelationships between technology, art an audiovisual design offered by the film challenge the standard solutions of the mainstream cinema and open an active zone of experimentation in the relations between design and fiction in the Latin American Cinema.

Keywords: Film - Design - Fiction - Epistemology - Art.

Resumo: O artigo examina o caso do longa-metragem brasileiro As boas maneiras, de Juliana Rojas e Marco Dutra, como uma experiência de design audiovisual enquadrada em uma epistemologia sulista. Partindo do questionamento das linhas abissais traçadas em sua diegese, o filme aponta para um horizonte pós-abissal no campo do cinema fantástico feito na América Latina. Por outro lado, as inter-relações entre tecnologia, arte e design audiovisual oferecidas pelo filme desafiam as soluções do cinema mainstream e abrem uma zona ativa de experimentação nas relações entre design e ficção Por outro lado, as inter-relações entre tecnologia, arte e design audiovisual oferecidas pelo filme desafiam 
as soluções comuns do cinema mainstream e abrem uma zona ativa de experimentação nas relações entre design e ficção no cinema feito na América Latina.

Palavras chave: Filme- Design - Ficção - Epistemologia - Arte.

[Las traducciones de los abstracts fueron supervisadas por el autor de cada artículo] 